\title{
A new class of hybrid super- supertetrahedral cluster and its assembly into a five-fold interpenetrating network
}

Article

Accepted Version

Vaqueiro, P., Makin, S., Tong, Y. and Ewing, S. J. (2017) A new class of hybrid super-supertetrahedral cluster and its assembly into a five-fold interpenetrating network. Dalton Transactions, 46 (12). pp. 3816-3819. ISSN 1364-5447 doi: https://doi.org/10.1039/C7DT00280G Available at https://centaur.reading.ac.uk/69262/

It is advisable to refer to the publisher's version if you intend to cite from the work. See Guidance on citing.

To link to this article DOI: http://dx.doi.org/10.1039/C7DT00280G

Publisher: Royal Society of Chemistry

All outputs in CentAUR are protected by Intellectual Property Rights law, including copyright law. Copyright and IPR is retained by the creators or other copyright holders. Terms and conditions for use of this material are defined in the End User Agreement.

www.reading.ac.uk/centaur 
Central Archive at the University of Reading

Reading's research outputs online 


\title{
Journal Name
}

\section{COMMUNICATION}

\section{A new class of hybrid super-supertetrahedral cluster and its assembly into a five-fold interpenetrating network}

Received 00th January 20xx, Accepted 00th January 20xx

\begin{abstract}
DOI: $10.1039 / \times 0 x \times 00000 x$
\end{abstract}
www.rsc.org/

We describe an entirely new type of tetrahedral cluster, representing a new level of structural hierarchy: a hybrid tetrahedron of supertetrahedra, formed by five T3 supertetrahedral clusters connected by bipyridyl linkers. Covalent assembly of these $37 \AA$ A super-supertetrahedra with smaller (10 ̊) T3 clusters results in the formation of a two-dimensional covalent network which contains pores in the mesoporous range.

Supertetrahedral clusters, with their well-defined sizes and compositions, lie at the boundary between colloidal quantum dots and molecular species. ${ }^{1}$ They exhibit interesting electronic and optical properties, which can be tuned by varying the cluster size and composition, and hence allow the investigation of quantum confinement effects at the lower size limit of colloidal quantum dots. ${ }^{2,3}$ Supertetrahedral clusters are also excellent building blocks for inorganic open-framework chalcogenides in which porosity is integrated with semiconductivity, and the resulting multifunctional materials are attractive candidates for a wide range of applications, including photocatalysis, ${ }^{4}$ ion-exchange ${ }^{5,6}$ or fast-ion conductivity. ${ }^{6,7}$ Linkage of supertetrahedral clusters with organic ligands, to form covalent hybrid networks, is also possible. ${ }^{8,9,10}$ This potentially provides an unprecedented capacity to yield materials with novel properties, arising from the synergistic interactions between the organic and inorganic components. However, only a small number of supertetrahedra-based hybrid networks have been reported to date $^{8,9,10}$ as exemplified by the supertetrahedral-cluster imidazolate frameworks, which adopt a diamond topology, and exhibit two- or three-fold interpenetration depending on the size of the supertetrahedral cluster. ${ }^{8}$

A variety of chalcogenide tetrahedral clusters, belonging to the supertetrahedral $(T n)$, penta-supertetrahedral $(\mathrm{P} n)$, and capped supertetrahedral $(\mathrm{C} n)$ series are known. ${ }^{11,12}$ These

\footnotetext{
a. Department of Chemistry, University of Reading, Reading RG6 6AD, UK. E-mail: p.vaqueiro@reading.ac.uk

b. Institute of Chemical Sciences, Heriot-Watt University, Edinburgh EH14 4AS, UK.

Electronic Supplementary Information (ESI) available: Experimental details, powder X-ray diffraction patterns and FT-IR data See DOI: 10.1039/x0xx00000x
}

clusters can be entirely inorganic, or can also be hybrid clusters in which some or all of the chalcogenide anions at the surface of the cluster have been replaced by ligands (often chalcogenolates). For Group 13 elements, known hybrid tetrahedral clusters, which contain covalently-bonded amines at the vertices, are limited to the $T n$ series (where $n$ is the number of metal layers in the cluster). These include T2 $\left[\mathrm{In}_{4} \mathrm{Te}_{9}(\mathrm{en})\right]^{6-}, 13 \mathrm{~T} 3\left[\mathrm{M}_{10} \mathrm{~S}_{16} \mathrm{~L}_{4}\right]^{2-}(\mathrm{M}=\mathrm{Ga}, \mathrm{In} ; \mathrm{L}=$ amine $){ }^{8,}, 14 \mathrm{~T} 4$ $\left[\ln _{16} \mathrm{Cd}_{4} \mathrm{~S}_{31} \mathrm{~L}_{4}\right]^{6-15}$ and T5 $\left[\mathrm{Cu}_{5} \mathrm{Ga}_{30} \mathrm{~S}_{52}(\mathrm{SH})_{2} \mathrm{~L}_{2}\right]^{11-}$ clusters. ${ }^{16}$ Herein, we describe a new class of hybrid supersupertetrahedral cluster (Figure 1), formed by replacing each atom in a tetrahedron by a hybrid supertetrahedral cluster. The linkage of the new super-supertetrahedral clusters with T3 clusters results in the formation of a five-fold interpenetrating network, which represents a completely new level of complexity in this remarkable family of materials.

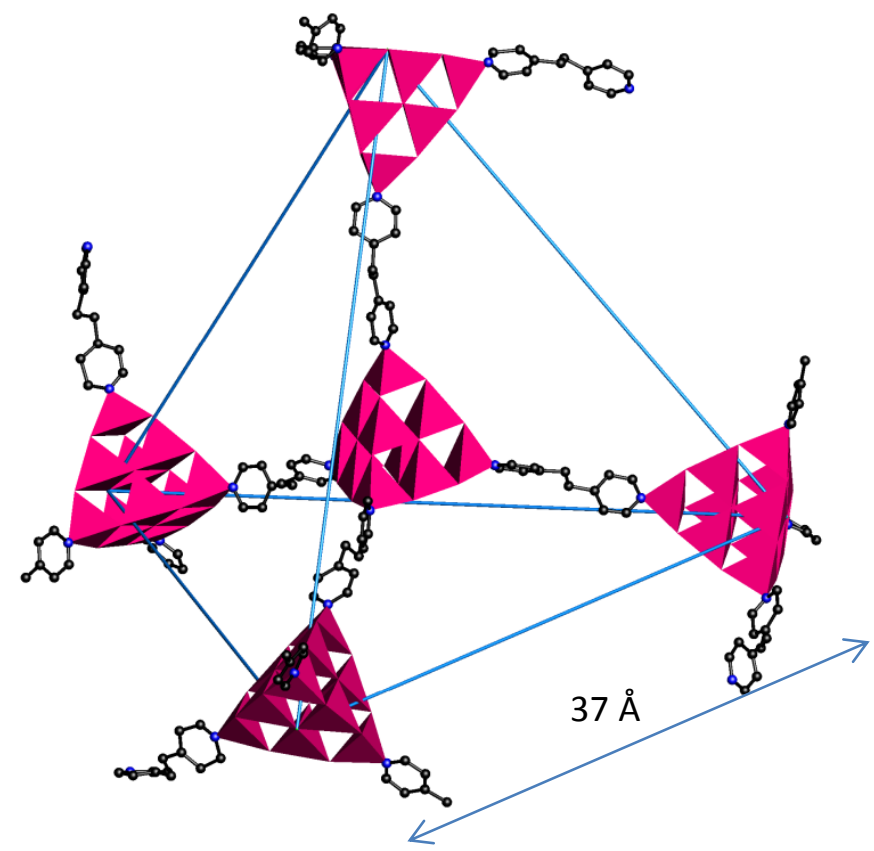

Figure 1. Polyhedral representation of the hybrid super-supertetrahedron, with Figure 1. Polyhedral representation of th
the tetrahedral edges outlined in blue. 
(a)

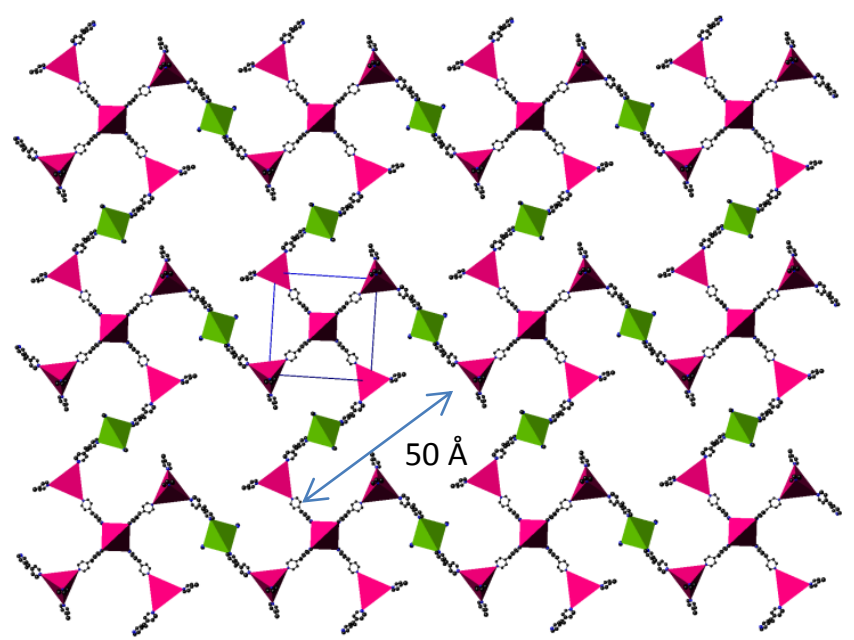

(b)

$40 \AA$

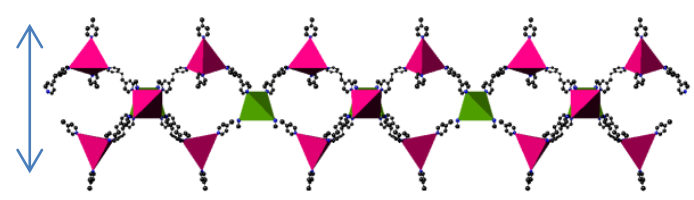

Figure 2. (a) Schematic view of one 2-dimensional covalent network of the title compound along [001]. (b) Single covalent network along [210]. Each T3 supertetrahedral cluster is represented by a single tetrahedron. T3 clusters in the super-supertetrahedra are shown in pink, and linking T3 supertetrahedra in

This material was initially prepared by solvothermal reaction of gallium, sulfur, 1,3-benzodiazole and 4-methylpyridine at $200^{\circ} \mathrm{C}$ for 5 days. ${ }^{17}$ The product of the reaction consisted of a small amount of yellow crystals of the title compound, numerous orange crystals of a previously reported phase containing the $\left[\mathrm{Ga}_{10} \mathrm{~S}_{16}\left(\mathrm{NC}_{6} \mathrm{H}_{7}\right)_{4}\right]^{2-}$ cluster, ${ }^{18}$ and a small amount of gallium metal. Following extensive optimisation to increase the yield of yellow crystals, it was found that 1,3benzodiazole was not required to prepare the title compound. ${ }^{19}$ Powder X-ray diffraction data of the product of the optimised reaction (ESI) indicates that the title compound is the main product of the reaction, although some orange crystals are still present.

Analysis of single-crystal X-ray diffraction data ${ }^{20}$ for the title compound revealed the presence of $37 \AA$ A tetrahedral building blocks (Figure 1), formed by replacing each atom in a tetrahedron by a T3 supertetrahedral cluster. The five T3 $\left[\mathrm{Ga}_{10} \mathrm{~S}_{16} \mathrm{~L}_{4}\right]^{2-}$ clusters are linked by bipyridyl ligands into this large tetrahedral unit, which constitutes the first example of a hybrid super-supertetrahedron, and is an unparalleled building block in supertetrahedra-based hybrid networks. This hybrid super-supertetrahedron is markedly different to $T p, q$ clusters, which can be regarded as Tn clusters in which core central atoms have been removed, ${ }^{21,22}$ and where individual $\mathrm{MS}_{4}$ tetrahedra are linked by sharing $\mathrm{S}^{2-}$ anions. It should be noted that the bipyridyl ligand is formed in situ during the solvothermal reaction. We have previously observed the in situ synthesis of 1,2,-di(4-pyridyl)ethane from similar reaction mixtures containing 4-methylpyridine, ${ }^{18}$ and it has also been reported that thermal degradation of pyridine derivatives can result in the formation of dipyridyl molecules. ${ }^{23}$

In the crystal structure of the material reported here, each hybrid super-supertetrahedron is linked by its four corners, via additional bipyridyl linkers, to four T3 clusters, and each T3 cluster is connected to two super-supertetrahedra. The remaining two vertexes of the two-connected T3 clusters are bonded to ethylamine, which is formed in situ via decomposition of the organic reagents under solvothermal conditions. ${ }^{10}$ The linkages between the super-supertetrahedra and the two-connected T3 clusters result in the formation of a two-dimensional covalent network (Figure 2), consisting of alternating two- and four-connected building units, and containing cross-shaped pores. Each arm of the cross-shaped pore has an aperture of approximately $50 \AA$. From a structural point of view, this covalent network presents multi-level hierarchy. Individual $\mathrm{MS}_{4}$ tetrahedra can be considered as the primary building units. There are three crystallographically distinct T3 clusters, which can be designated as the secondary building units, and the hybrid super-supertetrahedra, which are the tertiary building units, constitute the next level of structural hierarchy. The two-dimensional network described here constitutes the first example of a supertetrahedra-based hybrid network containing two types of building units, supersupertetrahedra and T3 clusters. (a)

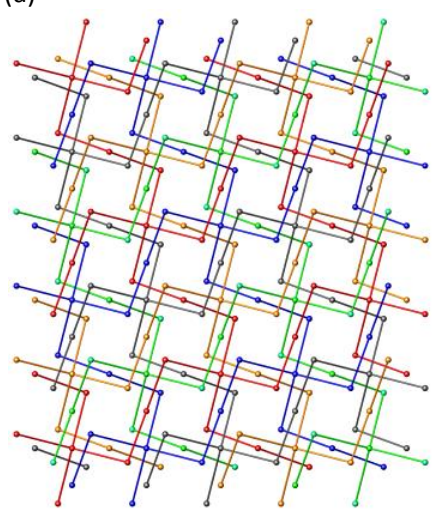

(b)

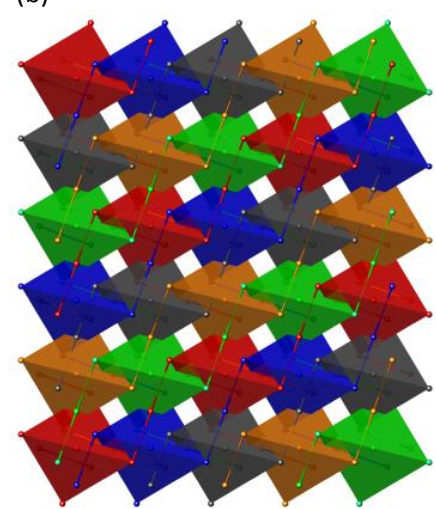

Figure 3. (a) Schematic representation of one layer of the title compound viewed along [001], showing the five interpenetrating networks. (b) Alternative polyhedral representation of one layer, illustrating the arrangement of supersupertetrahedra. Each node represents a T3 supertetrahedral cluster, and each of the five interpenetrating networks is shown in a different colour.

In the crystal structure reported here, layers, with an approximate thickness of $40 \AA$, are formed by interpenetration of five covalent two-dimensional networks, as illustrated in Figure 3. The five-fold interpenetration found here is unique in inorganic or hybrid supertetrahedra-based materials, although two- or even three-fold interpenetration is not unusual. ${ }^{8,24}$ This $^{\text {Tin }}$ high level of interpenetration is likely to be a consequence of the large size of the hybrid super-supertetrahedral clusters when compared to conventional Tn clusters.

Successive layers are stacked along the $c$-axis in an ABAB... sequence. Despite the five-fold interpenetration, the porosity of the crystal structure, which was determined using PLATON, ${ }^{25}$ is approximately $42 \%$, and appears to consist of large cavities and narrow channels of ca. $3 \AA$ oriented along the $a$ and $b$ axes. Eight methylpyridinium moieties per formula unit were located within the pores, but charge balancing 
would require the presence of additional protonated species, and significant residual electron density remained in the Fourier maps. Hence the proposed formula for this compound, taking into account the results of elemental analysis, ${ }^{26}$ is: $\left[\mathrm{C}_{6} \mathrm{H}_{8} \mathrm{~N}\right]_{14}\left[\left(\mathrm{Ga}_{10} \mathrm{~S}_{16}\right)_{7}\left(\mathrm{NC}_{2} \mathrm{H}_{7}\right)_{4}\left(\mathrm{NC}_{6} \mathrm{H}_{7}\right)_{8}\left(\mathrm{~N}_{2} \mathrm{C}_{12} \mathrm{H}_{12}\right)_{8}\right]$ $\left[\mathrm{C}_{6} \mathrm{H}_{8} \mathrm{~N}\right]_{14}\left[\left(\left(\mathrm{Ga}_{10} \mathrm{~S}_{16}\right)_{5}\left(\mathrm{NC}_{6} \mathrm{H}_{7}\right)_{4}\left(\mathrm{~N}_{2} \mathrm{C}_{12} \mathrm{H}_{12}\right)_{6}\right)\left(\left(\mathrm{Ga}_{10} \mathrm{~S}_{16}\right)\left(\mathrm{NC}_{2} \mathrm{H}_{7}\right)_{2}\right.\right.$ $\left.\left(\mathrm{N}_{2} \mathrm{C}_{12} \mathrm{H}_{12}\right)\right)_{2}$ ] when super-supertetrahedra and two-connected T3 clusters are expressed as individual components). FT-IR data (ESI) collected on ground single-crystals of this material is consistent with the presence of both aromatic rings and alkane groups. Thermogravimetric data (Figure 4), collected under an air atmosphere, indicates that weight loss occurs in multiple stages. The overall weight loss (53.6\%) is consistent with decomposition to $\mathrm{Ga}_{2} \mathrm{O}_{3}$, for which a theoretical value of $53.8 \%$ would be expected. The first weight loss, which occurs up to approximately $250^{\circ} \mathrm{C}$, can be assigned to the removal of the 14 methylpyridinium countercations from the pore space (calculated weight loss of $10.8 \%$ ). The weight at $600^{\circ} \mathrm{C}(57.8 \%)$ is reasonably consistent with the complete removal of all the organic components and the formation of an oxysulfide intermediate, $\mathrm{Ga}_{2} \mathrm{O}_{2} \mathrm{~S}$, which decomposes at approximately $680^{\circ} \mathrm{C}$ into the final $\mathrm{Ga}_{2} \mathrm{O}_{3}$ oxide.

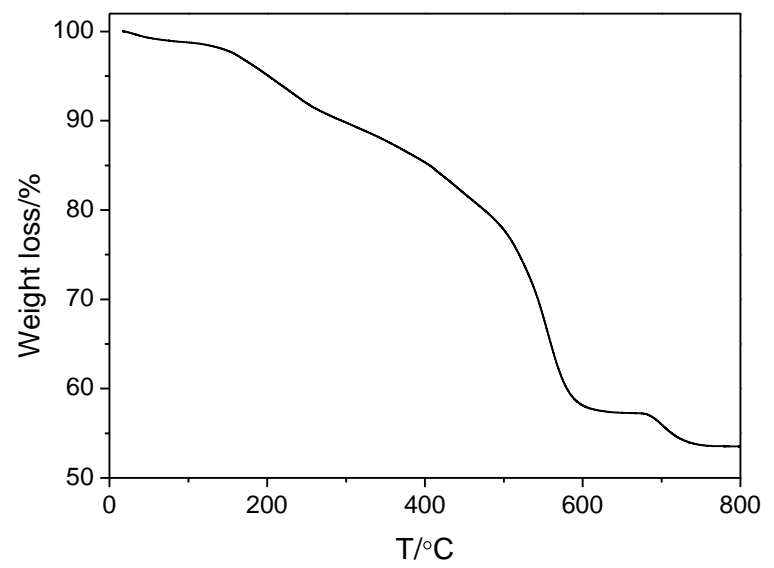

Figure 4. TGA data for the title compound.

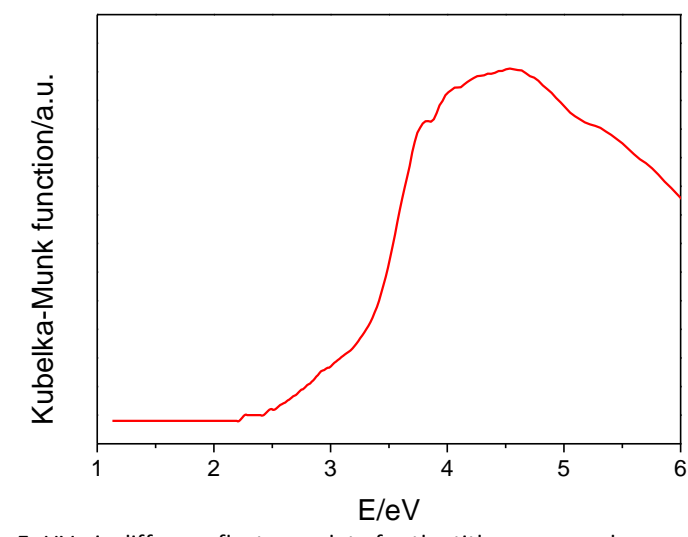

Figure 5. UV-vis diffuse reflectance data for the title compound.

UV-vis diffuse reflectance measurements (Figure 5) indicate that the optical band gap of this material is $3.17(7) \mathrm{eV}$, which is consistent with the observed yellow coloration. This value is comparable to those found for other gallium sulfides containing amine-functionalised T3 clusters. ${ }^{9,10,27}$ Marked red shifts in the optical band gap of hybrid supertetrahedra-based materials can sometimes occur, ${ }^{27}$ and may be related to the presence of $\pi-\pi$ interactions between aromatic rings and the formation of ion-pair charge-transfer salts. However, there is no evidence for $\pi-\pi$ interactions between the countercations and the anionic layers in the crystal structure of the title compound, and this is also consistent with the absence of a charge transfer band in the diffuse reflectance data reported here (Figure 5). Preliminary photoluminescence measurements on a wide range of hybrid supertetrahedra-based materials prepared in our laboratory, suggests that the nature of the ligands, the countercations and the three-dimensional arrangement of the supertetrahedral clusters have a marked influence on the emission behaviour of this family of materials, and detailed studies are currently underway to gain a better understanding of their optical properties.

In conclusion, we have presented here the first example of a new class of hybrid cluster, a hybrid super-supertetrahedron, formed by the linkage of five T3 clusters. Given that aminefunctionalised T4 and T5 clusters have already been described, ${ }^{15,16}$ we envisage that the synthesis of even larger hybrid super-supertetrahedra should be possible. The linkage of hybrid super-supertetrahedra with smaller T3 clusters found in the material described here represents a new level of structural hierarchy and complexity. The solvothermal synthesis of these hybrid materials is challenging, as it depends sensitively on the subtle interplay of a wide range of reaction variables, including the composition of reaction mixtures, $\mathrm{pH}$, temperature and time of reaction. Exploration of alternative approaches, such as ionothermal synthesis, which has already resulted in the preparation of large inorganic chalcogenidometallate superspheres ${ }^{28}$ and aminefunctionalised T5 clusters, ${ }^{16}$ may be required.

\section{Acknowledgements}

The authors would like to thank UK EPSRC for financial support through provision of a DTA studentship for Sarah J. Ewing. The authors also thank the University of Reading for a studentship for Sarah Makin, and for access to the Chemical Analysis Facility for powder X-ray diffraction and Thermogravimetric Analysis.

\section{Notes and references}

1 J. F. Corrigan, O. Fuhr and D. Fenske, Adv. Mater. 2009, 21, 1867.

2 T. Wu, L. Wang, X. Bu, V. Chau and P. Feng, J. Am. Chem. Soc. 2010, 132, 10823.

3 K. A. Nguyen, R. Pachter, P. N. Day and H. Su, J. Chem. Phys. 2015, 142, 234305.

4 K. Sasan, Q. Lin, C. Mao and P. Feng, Nanoscale, 2016, 8, 10913. 
5 X.-M. Zhang, D. Sarma, Y.-Q. Wu, L. Wang, Z.-X. Ning, F.-Q. Zhang and M. G. Kanatzidis, J. Am. Chem. Soc., 2016, 138, 5543.

6 Q. Lin, X. Bu, C. Mao, X. Zhao, K. Sasan and P. Feng, J. Am. Chem. Soc., 2015, 137, 6184.

7 N. Zheng, X. Bu and P. Feng, Nature, 2003, 426, 428.

8 T. Wu, R. Khazhakyan, L. Wang, X. Bu, S.-T. Zheng, V. Chau and P. Feng, Angew. Chem. Int. Ed. 2011, 50, 2536.

9 P. Vaqueiro and M. L. Romero, J. Am. Chem. Soc. 2008, 130, 9630.

10 P. Vaqueiro, M. L. Romero, B. C. Rowan and B. S. Richards, Chem. Eur. J. 2010, 16, 4462.

11 X. Bu, N. Zheng and P. Feng, Chem. Eur. J. 2004, 10, 3356.

12 P. Vaqueiro, Dalton Trans., 2010, 39, 5965.

13 Q. Zhang, I. Chung, J. I. Jang, J. B. Ketterson and M. G. Kanatzidis, Chem. Mater. 2009, 21, 12.

14 P. Vaqueiro and M. L. Romero, Chem. Commun. 2007, 3282.

15 T. Wu, X. Bu, P. Liao, L. Wang, S.-T. Zheng, R. Ma and P. Feng, J. Am. Chem. Soc. 2012, 134, 3619.

16 W.-W. Xiong, J.-R. Li, H. Bing, T. Bin, R.-F. Li, X.-L. Huanh, Chem. Sci., 2012, 3, 1200.

17 A mixture of gallium metal (140 mg, $2.01 \mathrm{mmol}$ ), sulfur (178 $\mathrm{mg}, 5.55 \mathrm{mmol}), 1,3$-benzodiazole $(120 \mathrm{mg}, 1.01 \mathrm{mmol})$ and 4-methylpyridine $(2.94 \mathrm{~mL}, 30.11 \mathrm{mmol})$ was loaded into a $23 \mathrm{~mL}$ Teflon-lined stainless steel autoclave. After stirring the mixture, the vessel was sealed, heated at $200^{\circ} \mathrm{C}$ for 5 days and then cooled down to room temperature at $1^{\circ} \mathrm{C} \mathrm{min}^{-1}$. The solid product was filtered and washed with methanol, acetone and deionized water.

18 P. Vaqueiro and M. L. Romero, Mater. Res. Soc. Symp. Proc. 2009, 1148E, 1148-PP10-07.

19 The optimal reaction conditions were established as: gallium metal (170.6 mg, $2.5 \mathrm{mmol})$, sulfur ( $158.5 \mathrm{mg}, 5 \mathrm{mmol}$ ) and 4-methylpyridine $(2.9 \mathrm{ml}, 30 \mathrm{mmol})$ heated in a $23 \mathrm{~mL}$ autoclave at $200^{\circ} \mathrm{C}$ for 6 days.

20 Single-crystal $X$-ray diffraction data were collected using a Bruker X2 APEX 2 diffractometer (Mo $\mathrm{K}_{\alpha} \lambda=0.71073 \AA$ ), at $100 \mathrm{~K}$. The structure was solved using the program SIR92 and the model refined using CRYSTALS. The $\mathrm{C}$ and $\mathrm{N}$ atoms of the amine molecules were modelled isotropically. The data were treated with SQUEEZE, to correct the effect of the disordered organic cations. Crystallographically determined formula: $\left[\mathrm{C}_{5} \mathrm{H}_{6} \mathrm{~N}\right]_{8}\left[\left(\mathrm{Ga}_{10} \mathrm{~S}_{16}\right)_{7}\left(\mathrm{NC}_{2} \mathrm{H}_{7}\right)_{4}\left(\mathrm{NC}_{6} \mathrm{H}_{7}\right)_{8}\left(\mathrm{~N}_{2} \mathrm{C}_{12} \mathrm{H}_{12}\right)_{8}\right], \mathrm{M}=$ 11503.92, tetragonal, space group $14{ }_{1} / a, a=24.003(3) \AA$ 85.886(13) $\AA ̊ 丿, V=49484(12) \AA^{3}, Z=4$. Crystal dimensions: $0.05 \times 0.05 \times 0.05 \mathrm{~mm}^{3} .25427$ reflections measured, 25427 unique, 11982 observed with $I>3 \sigma(I)$. Final values of $R(F)$ and $\mathrm{WR}(\mathrm{F})$ were 0.0643 and 0.0719 respectively. CCDC-1525942 contains the supplementary crystallographic data for this paper. These data can be obtained free of charge from The Cambridge Crystallographic Data Centre.

$21 \mathrm{H}$. Li, J. Kim, M. O'Keeffe and O. M. Yaghi, Angew. Chem. Int. Ed., 2003, 42, 1819.

22 Q. Lin, X. Bu and P. Feng, Chem. Commun., 2014, 50, 4044.

23 C. D. Hurd and J. I. Simon, J. Am. Chem. Soc. 1962, 84, 4519.

24 X. Han, J. Xu, Z. Wang, D. Liu and C. Wang, Chem Commun., 2015, 51, 3919.

25 A.L. Spek, Acta Cryst. A, 1990, 46, c34.

26 Elemental analysis for single crystals of the title compound: Found C 26.09, H 2.53, N 4.68\%; calc. $\left(\mathrm{Ga}_{70} \mathrm{~S}_{112} \mathrm{C}_{236} \mathrm{H}_{292} \mathrm{~N}_{42}\right)$ : C 23.26, H 2.41; N 4.83\%

27 P. Vaqueiro and M. L. Romero, Inorg. Chem. 2009, 48, 810.

28 S. Santner, S. Yogendra, J. J. Weigand and S. Dehnen, Chem. Eur. J., 2017, 23, 1999. 